\title{
I see what you are doing: Student views on lecturer use of Tablet PCs in the engineering mathematics classroom
}

\author{
Peter Maclaren, David Wilson and Sergiy Klymchuk \\ Auckland University of Technology, New Zealand
}

Mathematically intensive engineering subjects at a tertiary level have traditionally been taught in classroom environments using whiteboards or blackboards. This paper reports on student views of the effectiveness of board and alternative technologies used within existing classroom contexts. Students in this study revealed a strong preference for the use of pen-enabled Tablet PCs as a delivery technology. The maintenance of a handwritten approach, combined with ready visibility of material, support for inclusion of other digital outputs and post-class access to material, were key factors influencing student preferences. Although this introduction of technology did not involve substantive changes in classroom pedagogical approaches, the study suggests that the Tablet PC technology may facilitate future development of more flexible approaches.

\section{Introduction}

A number of studies have examined factors that may influence lecturer adoption of new technologies in educational environments (Abrahams, 2010; Elzarka, 2012; Rogers, 1983; Schoepp, 2005), including interactions between changes in pedagogy and discipline content (Harris, Mishra, \& Koehler, 2009). Annan (2008, p. 16) noted that faculty "must be convinced of the relevance of the technology to what they do in the classroom if they are to be convinced to change their current practices". However, the focus here is not directly on the teacher viewpoint, but on the student viewpoint; of their perceptions of teacher use of different technologies for the presentation of mathematically based material in lecture theatres and classrooms in a tertiary campus environment.

Traditional delivery modes in classroom environments have involved the use of handwritten material on a board in association with what have been described as pedagogically conservative lecture approaches. The term "chalk and talk" is commonly used to describe such teaching methods, which have been criticised as being transmissive, teacher centric and ineffective (Bates, 2014). However, these criticisms have generally been made without consideration of the disciplines involved, and Fox and Artemeva (2011) determined that in the context of mathematics education what they termed a "chalk talk" approach can be "pedagogically interactive, meaningful, and engaging" (p. 87), even when it is essentially transmissive. A valuable component of the lecture can be the explicit modelling of expert thinking (Bates, 2014; Bergsten, 2007; McKeachie \& Svinicki, 2013) which, in the context of mathematics education, Greiffenhagen (2008, p. 11) described as "situations in which an experienced mathematician demonstrates mathematical expertise to novices as an important part of their progressive induction into professionally competent autonomous mathematical practice”.

Although writing boards (blackboards or whiteboards) have remained a preferred delivery technology for many university teachers of mathematics disciplines (Greiffenhagen, 2014), the centralisation of responsibility for the management of teaching rooms in many institutions has encouraged the development of standardised technologies in generic rooms. The data projector, connected to a standard desktop computer, has become a standard configuration in many university teaching spaces (AETM, 2015), including in the study institution, with less emphasis being placed on the provision of large-scale traditional writing boards. However, the standard computer, with only keyboard and mouse, does not support handwritten inputs, and the use of software such as PowerPoint to display slides of prepared material has become common even in the mathematics lecture. The document camera with data projector is now a recommended option for large and medium university learning spaces (AETM, 2015), providing an option (and sometimes the only option) for the display of handwritten material. More recently the development of digitisers, either within stand-alone monitors or incorporated in devices such as the pen-enabled Tablet PC (penTPC), has provided another option for the projection of live handwritten material (Maclaren, 2014). 
In the context of this study the introduction of technologies has not primarily involved changes to traditional pedagogical approaches and might be seen as facilitating their continuance. However, the purpose of this study is not to endorse any particular pedagogical approach, but to examine how technologies can be used to support any approach requiring the presentation of live handwritten material in a classroom (and potentially, online) environment. Although lecturers will have their own personal preferences for delivery methods and technologies, formed by their prior experiences, this study examined whether students share these views.

\section{Study approach}

This study was conducted as part of an ongoing design-based research (DBR) project, which aims to guide the introduction and use of penTPC technology for the teaching of mathematically intensive (MI) disciplines in a university environment. The rationale for the project approach is encapsulated in the description of DBR by Anderson and Shattuck (2012, p. 16):

Being situated in a real educational context provides a sense of validity to the research and ensures that the results can be effectively used to assess, inform, and improve practice in at least this one (and likely other) contexts.

Using the DBR terminology of Sandoval (2014), in this project there is an underlying conjecture that the penTPC can be used by lecturers in ways that enhance learning and engagement in MI disciplines; that this enhancement would derive from the affordance of the penTPC interface to better facilitate communication of non-linguistic content (Oviatt, Cohen, Miller, Hodge, \& Mann, 2012, pp. 1-2); and that developments need to proceed with an understanding of what is actually happening in relevant educational settings, and why it is happening (Selwyn, 2010, pp. 69-70). From a pragmatic perspective, the fact that the penTPC is already being introduced within current institutional contexts, but without a centrally managed development plan and without guidance of a clearly articulated theoretical framework, provides impetus to articulate appropriate design conjectures and connect the embodied tools, tasks and practices, and mediating processes with appropriate theory.

Although an ongoing concern of the DBR project includes how the device may enable alternative pedagogical approaches, and how they and their associated good use practices might be promulgated, the focus of this initial study is more exploratory. It aims to identify what is happening, and what might be developed as good or desirable practices, within current pedagogic approaches.

Students from six distinct (in date, time and/or location) class sessions involving six lecturers teaching five different subjects within an Australasian university were surveyed in 2015, with ethics approval granted by the university ethics committee. The selected sessions represented a convenience sample, based on timetabling and lecturer availability, from sessions in which the lecturer was using a penTPC in teaching MI engineering subjects. The sessions covered a range of levels, from first-year to third-year undergraduate level, with subjects including both general engineering mathematics and more specialised discipline areas such as mechanical engineering design and control engineering. The lecturers involved had varying levels of experience in the use of a penTPC, from those in their first semester of use to those with over three years of experience. The students in the classes surveyed would have had prior experience with a range of delivery technologies (including traditional whiteboard, document cameras and PowerPoint, as well as the penTPC), although not all would have had experience with all those technologies. Students would also have experienced variations in different classes in how a lecturer may have used specific technologies, and in lecturer expertise with those technologies. Students were asked to give feedback based on the range of their experiences (across class sizes, rooms, subjects and lecturers), and not just on the experiences in that one session (or class) in which they were surveyed.

At the conclusion of the selected sessions students were invited by the researcher, who was not teaching the class, to complete an optional anonymous paper-based survey. A paper-based survey (rather than an online questionnaire) was used in expectation of achieving a high response rate, which was attained, with the 480 
survey returns representing over 95\% of students present in the sessions. Students were given the option to complete and return survey forms outside of the session, but no further forms were returned outside the session in which they were distributed.

The aspects of the survey that are reported in this paper relate to the questions that asked the students their perception of the effectiveness of five classroom presentation technologies: basic PowerPoint; PowerPoint with live handwritten annotations (penTPC with PowerPoint); whiteboard; pen-enabled Tablet PCs used to develop handwritten notes in OneNote (penTPC with OneNote); and document cameras . All but the whiteboard option involved projection of the material using a data projector and screen (DPSc). Students rated the perceived effectiveness of each mode on a 5-point Likert-style scale (very ineffective; very poor; ineffective/poor; average; effective/good; very effective/very good or N/A, no opinion), using their own interpretation of these terms, with analysis focusing on comparative ratings. Primarily non-parametric quantitative methods were used in the comparative analysis of effectiveness ratings and are described in detail in the following section.

As appropriate to the DBR approach, the study sought not just to identify quantitative differences in student ratings of modes, but to gain an understanding of possible reasons behind those ratings, so as to guide policy development. Thus, students were also invited to comment, in a three-line free text area, headed "Comment (like/dislike)" following each individual effectiveness rating. As with "effectiveness", the terms "like/dislike”, were not formally defined but left to student interpretation. As apparent in the nature of their comments, student expressions of likes/dislikes were generally related closely to, and interpreted in the context of, their perceptions of mode effectiveness, and vice versa. Not all students provided comments, and where they did, the comments varied from single words to a few sentences, with a short phrase the most common.

A thematic analysis method was applied in the analysis of comments, involving six phases as described by Braun and Clarke (2006). Firstly, all responses were transcribed verbatim into Excel and examined (Phase 1) and an initial set of categories established within each mode (Phase 2). Many comment phrases were explicit in meaning (for example, “can’t see” or “out of focus”), and these guided establishment of common functional categories. Spreadsheet columns were established on the basis of these categories, and text responses entered into appropriate columns. Thus, full descriptions were retained along with numeric summary data (or words with numbers, as advocated by Miles and Huberman, 1994, p. 11), facilitating the ongoing search for and definition and review of themes (Phases 3, 4, 5) within grouped column categories. Identified categories and themes (Phase 6), together with a synthesis of quantitative and qualitative data, are reported in the analysis and conclusions sections.

\section{Comparison of effectiveness ratings}

A summary of student effectiveness ratings of the different modes, showing percentages and response counts for ratings within each mode, is shown in Table 1. For ease of referencing, a numerical code was assigned to each category, with -2 as very poor/very ineffective, -1 as poor/ineffective (and collectively, as negative ratings), with 0 as average, and (collectively as positive ratings) 1 as good/effective and 2 as very good/very effective. The data in Table 1 is displayed in comparative stacked percentage column charts in Figure 1. To aid visual comparisons between modes and emphasise the nature of differences, the vertical position of bars in the chart is adjusted to centre the average effectiveness categories on a common datum line. Thus, for each mode, the portion of the bar above the datum represents the proportion of students giving the mode a positive rating plus half of those assigning an average rating, and the portion below the datum represents the percentage of students who assigned a negative rating plus half of those assigning an average rating.

The percentages of students who assign a positive rating and percentages who assign a negative rating are listed by mode in Table 2 and may be visualised in Figure 1 as the top two segments and bottom two segments, respectively, of each bar. Figure 1 shows an increasing preference from standard PowerPoint (31\% positive), to document camera (41\% positive), to whiteboard (61\% positive), and then to the penTPC using PowerPoint with annotation (73\% positive), and with penTPC with OneNote software (84\% positive) the most preferred option. Standard PowerPoint is the only mode that does not incorporate live handwritten material. 
Table 1

Ratings of effectiveness by delivery mode

\begin{tabular}{|c|c|c|c|c|c|c|c|c|c|c|c|}
\hline & & \multicolumn{2}{|c|}{ PowerPoint } & \multicolumn{2}{|c|}{$\begin{array}{c}\text { Document } \\
\text { camera }\end{array}$} & \multicolumn{2}{|c|}{ Whiteboard } & \multicolumn{2}{|c|}{$\begin{array}{l}\text { penTPC with } \\
\text { PowerPoint }\end{array}$} & \multicolumn{2}{|c|}{$\begin{array}{l}\text { penTPC with } \\
\text { OneNote }\end{array}$} \\
\hline & & $n$ & $\%$ & $n$ & $\%$ & $n$ & $\%$ & $n$ & $\%$ & $n$ & $\%$ \\
\hline \multirow{3}{*}{ : } & $\begin{array}{l}2 \text { very good/ } \\
\text { very effective }\end{array}$ & 34 & $8 \%$ & 49 & $13 \%$ & 115 & $26 \%$ & 116 & $26 \%$ & 195 & $41 \%$ \\
\hline & 1 good/effective & 103 & $23 \%$ & 108 & $28 \%$ & 153 & $35 \%$ & 211 & $47 \%$ & 203 & $43 \%$ \\
\hline & 0 average & 193 & $43 \%$ & 143 & $37 \%$ & 111 & $25 \%$ & 101 & $23 \%$ & 54 & $11 \%$ \\
\hline \multirow{3}{*}{ 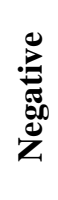 } & -1 poor/ineffective & 81 & $18 \%$ & 53 & $14 \%$ & 43 & $10 \%$ & 14 & $3 \%$ & 8 & $2 \%$ \\
\hline & $\begin{array}{l}\text {-2 very poor/ } \\
\text { very ineffective }\end{array}$ & 33 & $7 \%$ & 33 & $9 \%$ & 19 & $4 \%$ & 6 & $1 \%$ & 12 & $3 \%$ \\
\hline & Total responses & 444 & $100 \%$ & 386 & $100 \%$ & 441 & $100 \%$ & 448 & $100 \%$ & 472 & $100 \%$ \\
\hline
\end{tabular}

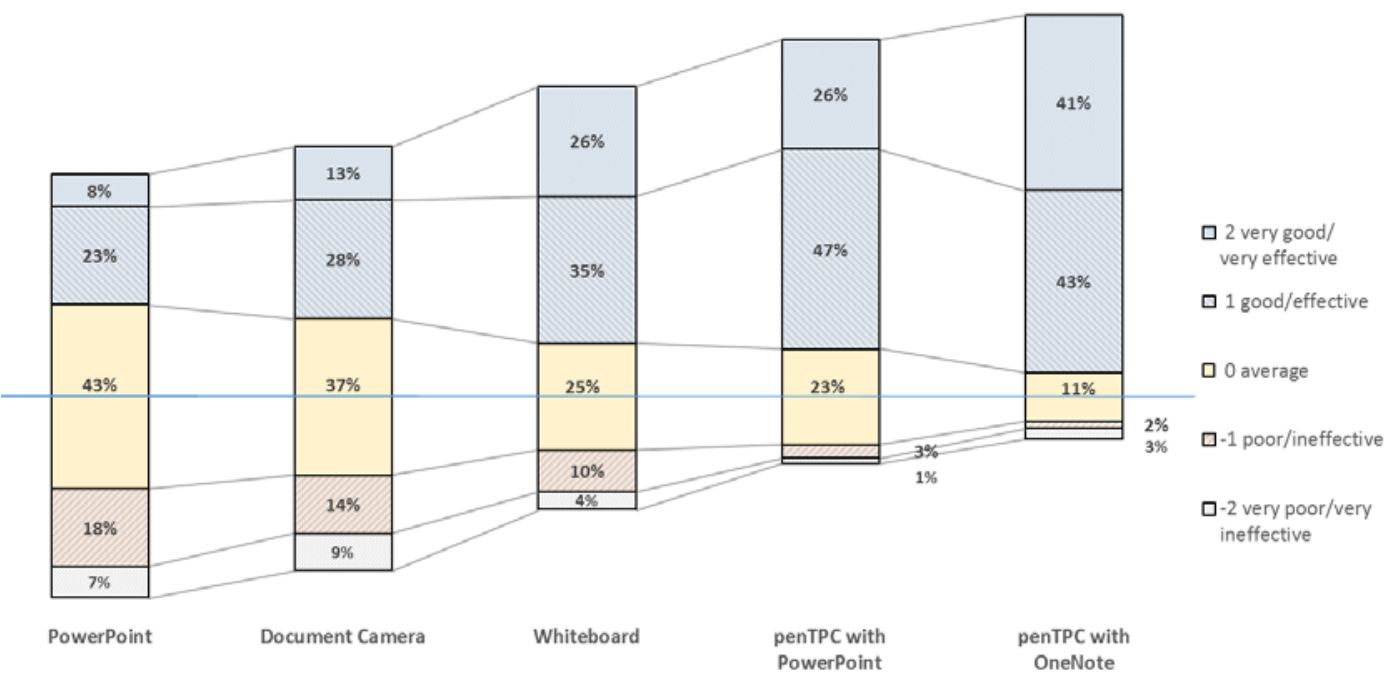

Figure 1. Student ratings of mode effectiveness. Bars divisions show the breakdown of ratings for each technology mode as percentages (rounded). Bar vertical position is adjusted to align the midpoints of the average rating category.

Although the very high rates of return of surveys forms suggest the sample statistics provide good indicators of the population of students attending lectures, a conservative approach is taken to analysis of the sample values. Methods appropriate to analysis of ordinal data are used here (Cliff, 1993; Grissom \& Kim, 2005), and percentages are used in expressing findings to facilitate interpretation (Knapp, 2009). A Chi-square analysis on response numbers in Table 1 confirms that there is a statistically significant difference $(\chi 2=418.03, \mathrm{df}=16, p$ value $<2$ x 10-16) between the overall distributions across the different modes.

A more detailed analysis was carried out using the Marascuilo procedure (Marascuilo, 1966; Prins, 2013) focusing on the differences in proportions of positive ratings for modes, as listed in Table 2. Results of pairwise comparisons using R software (Bedford, 2013; R Project, 2015), shown in Table 3, determined that all differences were significant at a 99\% confidence level except for the difference between PowerPoint and document camera modes, which was significant at a $90 \%$ level. 
Table 2

Summary of ratings by mode

\begin{tabular}{|c|c|c|c|c|c|c|c|c|c|c|}
\hline & \multicolumn{2}{|c|}{ PowerPoint } & \multicolumn{2}{|c|}{$\begin{array}{l}\text { Document } \\
\text { camera }\end{array}$} & \multicolumn{2}{|c|}{ Whiteboard } & \multicolumn{2}{|c|}{$\begin{array}{l}\text { penTPC with } \\
\text { PowerPoint \& } \\
\text { annotation }\end{array}$} & \multicolumn{2}{|c|}{$\begin{array}{c}\text { penTPC + } \\
\text { OneNote }\end{array}$} \\
\hline & $n$ & $\%$ & $n$ & $\%$ & $n$ & $\%$ & $n$ & $\%$ & $n$ & $\%$ \\
\hline $\begin{array}{l}\text { Positive rating } \\
1 \text { effective } \\
2 \text { very effective }\end{array}$ & 137 & $31 \%$ & 157 & $41 \%$ & 268 & $61 \%$ & 327 & $73 \%$ & 398 & $84 \%$ \\
\hline $\begin{array}{l}\text { Negative rating } \\
-1 \text { ineffective/ } \\
\text {-2 very } \\
\text { ineffective }\end{array}$ & 114 & $26 \%$ & 86 & $22 \%$ & 62 & $14 \%$ & 20 & $4 \%$ & 20 & $4 \%$ \\
\hline
\end{tabular}

Table 3

Marascuilo procedure analysis. Pairwise comparisons of the percentage of students assigning a positive $(+1$ or +2 ) rating. Observed differences that exceed the critical value at the designating confidence level are indicated as significant (Y); shaded cells indicate significance at a 99\% confidence level.

\begin{tabular}{|c|c|c|c|c|}
\hline & Document camera & Whiteboard & penTPC with PPT & $\begin{array}{l}\text { penTPC with } \\
\text { OneNote }\end{array}$ \\
\hline PowerPoint & $\begin{array}{l}\text { Obs. diff }=9.8 \% \\
\text { Crit val } 99 \%=12.1 \% \mathbf{~ N} \\
\text { Crit val } 90 \%=9.3 \% \mathbf{Y}\end{array}$ & $\begin{array}{l}\text { Obs. diff }=29.9 \% \\
\text { Crit val } 99 \%=11.6 \% \mathbf{Y}\end{array}$ & $\begin{array}{l}\text { Obs. diff }=42.1 \% \\
\text { Crit val } 99 \%=11.1 \% \mathbf{Y}\end{array}$ & $\begin{array}{l}\text { Obs. diff }=53.5 \% \\
\text { Crit val } 99 \%=10.0 \% \mathbf{Y}\end{array}$ \\
\hline $\begin{array}{l}\text { Document } \\
\text { camera } \\
\text { Whiteboard } \\
\text { penTPC } \\
\text { with } \\
\text { PowerPoint }\end{array}$ & & $\begin{array}{l}\text { Obs. diff }=20.1 \% \\
\text { Crit val } 99 \%=12.4 \% \mathbf{Y}\end{array}$ & $\begin{array}{l}\text { Obs. } \text { diff }=32.3 \% \\
\text { Crit val } 99 \%=11.9 \% \mathbf{Y} \\
\text { Obs. diff }=12.2 \% \\
\text { Crit val } 99 \%=11.4 \% \mathbf{Y}\end{array}$ & $\begin{array}{l}\text { Obs. diff }=43.6 \% \\
\text { Crit val } 99 \%=11.0 \% \mathbf{Y} \\
\text { Obs. diff }=23.6 \% \\
\text { Crit val } 99 \%=10.4 \% \mathbf{Y} \\
\text { Obs. diff = } 11.3 \% \\
\text { Crit val } 99 \%=9.8 \% \mathbf{Y}\end{array}$ \\
\hline
\end{tabular}

\section{Effect size}

Attention is now directed at determining the practical importance of the differences, as measured by effect sizes (Coe, 2002). In this context we are concerned whether the differences between ratings of alternative technologies are meaningfully large enough to justify a preference for one technology over another. For this ordinal data, Cliff's Delta (Cliff, 1993) is used as an appropriate measure (Grissom \& Kim, 2005, p. 107; Hess \& Kromrey, 2004; Kraemer \& Kupfer, 2006; Peng \& Chen, 2014; Romano, Kromrey, Coraggio, Skowronek, \& Devine, 2006). Cliff's Delta is also known as the “dominance measure of effect size (DM)” (Grissom \& Kim, 2005), and as the success rate difference (SRD) (Kraemer \& Kupfer, 2006). The latter terminology (SRD) is used here, with values listed as percentages (rather than proportions) to aid interpretation (Brooks, Dalal, \& Nolan, 2014; Knapp, 2009) and allow the values to be directly related to the percentage values in the Tables 1 and 2 and Figure 1. SRD evaluates the effect size in terms of estimates of two proportions: the proportion of observations in which a rating of one mode is higher than an alternative $(\mathrm{P}(\mathrm{Y}>\mathrm{X})$, minus the probability that it be lower $(\mathrm{P}(\mathrm{X}>\mathrm{Y})$ (Grissom \& Kim, 2005). It describes an overall net benefit (or "success”) of one approach over the other.

An SRD\% value of 0\% indicates there is no overall effect in using different approaches, (meaning that on average, there is no expected differences between mode ratings). An absolute value of 1 (|SRD\%|=100\%) would indicate the mode is preferred over the other by all respondents; the closer $|\mathrm{SRD} \%|$ is to $100 \%$, the stronger the effect, with the sign indicating the direction of the preference. In this study SRD values are calculated using a paired case analysis, comparing for each student their rating of one mode with their rating for the other mode (rather than comparing one student's ratings across all other students). This use of a paired data approach 
reduces potential effects of different interpretations of effectiveness and the rating scale by students; the analysis reflects the individual student's preferences for one mode over another, rather than quantifying their absolute ratings.

Results of the calculations for SRD using Rogmann's ordinal dominance statistics (ORDDOM) package (Rogmann, 2013) for $\mathrm{R}$ statistical software are displayed in Table 4, together with the two component probabilities, $\mathrm{P}(\mathrm{Y}>\mathrm{X})$ and $\mathrm{P}(\mathrm{X}>\mathrm{Y})$, as percentages. To aid interpretation, effect sizes in Table 4 have been categorised (and shaded) as small (S: SRD $\%<10 \%$ ), medium-small (MS: $10 \% \leq \mathrm{SRD} \%<25 \%$ ), medium large (ML: $25 \% \leq$ SRD $\%<50 \%$ ), and large (L: SRD\% $\geq 50 \%$ ). Table 4 also gives 95\% confidence intervals for the effect sizes, as calculated using ORDDOM, based on an analysis by Feng (2007) and Feng and Cliff (2004).

Table 4

Effect size: Success rate difference (SRD\%)

\begin{tabular}{|c|c|c|c|c|}
\hline & $\begin{array}{c}\text { Document } \\
\text { camera }\end{array}$ & Whiteboard & $\begin{array}{c}\text { penTPC with } \\
\text { PowerPoint }\end{array}$ & $\begin{array}{l}\text { penTPC with } \\
\text { OneNote }\end{array}$ \\
\hline PowerPoint & $\begin{array}{l}\text { SRD\% }=9.5 \% \mathrm{~S} \\
(37.5 \%-28 \%) \\
\text { C.I: } 1 \%-18 \%\end{array}$ & $\begin{array}{l}\text { SRD } \%=31 \% \text { ML } \\
(54 \%-22 \%) \\
\text { C.I: } 23 \%-39 \%\end{array}$ & $\begin{array}{l}\text { SRD\% }=56 \% \text { L } \\
(62 \%-6 \%) \\
\text { C.I: } 50 \%-61 \%\end{array}$ & $\begin{array}{l}\text { SRD } \%=60 \% \mathbf{L} \\
(67 \%-7 \%) \\
\text { C.I: } 54 \%-66 \%\end{array}$ \\
\hline $\begin{array}{l}\text { Document } \\
\text { camera }\end{array}$ & & $\begin{array}{l}\text { SRD } \%=23 \% \mathrm{MS} \\
(43 \%-20 \%) \\
\text { C.I: } 15 \%-31 \%\end{array}$ & $\begin{array}{l}\text { SRD } \%=38 \% \text { ML } \\
(51 \%-13 \%) \\
\text { C.I: } 31 \%-45 \%\end{array}$ & $\begin{array}{l}\text { SRD } \%=55 \% \text { L } \\
(60 \%-5 \%) \\
\text { C.I: } 49 \%-60 \%\end{array}$ \\
\hline Whiteboard & & & $\begin{array}{l}\text { SRD } \%=12 \% \text { MS } \\
(39 \%-27 \%) \\
\text { C.I: } 5 \%-20 \%\end{array}$ & $\begin{array}{l}\text { SRD } \%=30 \% \text { ML } \\
(45 \%-15 \%) \\
\text { C.I: } 23 \%-36 \%\end{array}$ \\
\hline $\begin{array}{l}\text { penTPC } \\
\text { with } \\
\text { PowerPoint }\end{array}$ & & & & $\begin{array}{l}\text { SRD } \%=20 \% \text { MS } \\
(36 \%-16 \%) \\
\text { C.I: } 13 \%-26 \%\end{array}$ \\
\hline \multicolumn{5}{|c|}{$\begin{array}{l}\text { Cell key: Each cell shows SRD\% together with component probabilities as percentages }(\mathrm{P}(\mathrm{X}>\mathrm{Y})-\mathrm{P}(\mathrm{Y}>\mathrm{X})) \\
\text { and } 95 \% \text { confidence intervals for SRD\%. }\end{array}$} \\
\hline Effect size & $\begin{array}{l}\text { SRD } \%<10 \% \\
\text { S Small effect }\end{array}$ & $\begin{array}{l}10 \% \leq \mathrm{SRD} \%<25 \% \\
\text { MS medium-small }\end{array}$ & $\begin{array}{l}25 \% \leq \text { SRD } \%<50 \% \\
\text { ML medium-large }\end{array}$ & $\begin{array}{l}\text { SRD } \% \geq 50 \% \\
\text { L Large }\end{array}$ \\
\hline
\end{tabular}

The effect sizes confirm the penTPC with OneNote mode to be the most favoured, with a 60\% SRD (evaluated as the percentage who rated this mode better than the PowerPoint mode, minus the percentage who rated it worse) over the PowerPoint mode, a net 55\% preference over the Document camera mode, and a net 30\% preference over the whiteboard mode. The penTPC with OneNote mode also showed a net 20\% preference over the other penTPC mode (penTPC with PowerPoint). These effect sizes are also confirmed as statistically meaningful, as none of the confidence intervals include zero.

Although it is recognised that there are arguments against using interval scales and parametric methods with ordinal data, a reasoned assignment of an interval scale to the ordinal categories here can generate a useful raw score measure and aid interpretation and communication of results in the context of the study (Baguley, 2009; Velleman \& Wilkinson, 1993). We are concerned here with making judgements on quality improvements, and a scale that gives a stronger positive emphasis to a desired goal of "very good" (rather than just "good"), and a stronger negative emphasis to "very poor" (rather than just "poor") may be useful. Applying a consistent interval scale of $-2,-1,0,1,2$ across all the modes, the mean ratings for the modes were calculated and are shown in Table 5 together with a 95\% confidence interval for these means, the standard deviation, and sample size for each mode. These means, with a 95\% confidence interval, are displayed in the chart in Figure 2. 
Table 5

Parametric summary statistics for modes

(Note: Expressed as category units, with categories assigned values -2, -1, 0, 1, 2)

\begin{tabular}{lccccc}
\hline & PowerPoint & $\begin{array}{c}\text { Document } \\
\text { camera }\end{array}$ & Whiteboard & $\begin{array}{c}\text { penTPC with } \\
\text { PowerPoint }\end{array}$ & $\begin{array}{c}\text { penTPC with } \\
\text { OneNote }\end{array}$ \\
\hline Mean $x$ & 0.05 & 0.23 & 0.68 & 0.93 & 1.19 \\
C.I. (95\%) & $(-0.4-0.15)$ & $(0.12-0.34)$ & $(0.58-0.79)$ & $(0.85-1.01)$ & $(1.11-1.27)$ \\
Std devs & 1.0 & 1.1 & 1.1 & 0.85 & 0.89 \\
\hline$n$ & 444 & 386 & 441 & 448 & 472 \\
\hline
\end{tabular}

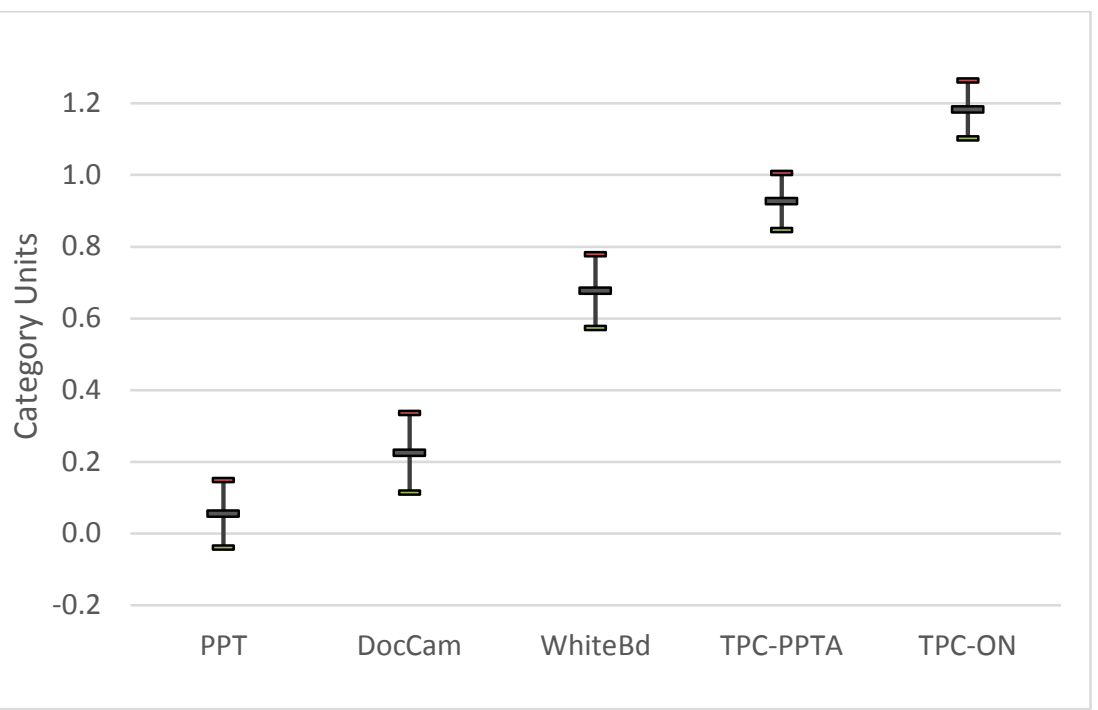

Figure 2. Mean effectiveness rating by mode (with 95\% C.I.) (Note: Based on category values -2, -1, 0, 1, 2)

Differences between the mean rating for each mode, denoted as $\Delta m$ in Table 6, provide a simple comparative measure of effect size, measured in units of "number of categories" of shift. As expected, Table 6 reveals a similar relationship to that shown in the ordinal analysis. The penTPC with OneNote mode is rated best, being more than one category unit better than PowerPoint, and on average one-half a category improvement over whiteboard. PowerPoint is rated the least effective, and the document camera only slightly better.

Table 6

Differences between means ( $\Delta m$ ) measured in category units

\begin{tabular}{|c|c|c|c|c|}
\hline & Document camera & Whiteboard & $\begin{array}{l}\text { penTPC with } \\
\text { PowerPoint }\end{array}$ & $\begin{array}{l}\text { penTPC with } \\
\text { OneNote } \\
\end{array}$ \\
\hline PowerPoint & $\Delta m=0.17 \mathrm{~S}$ & $\Delta m=0.63 \mathbf{M L}$ & $\Delta m=0.88 \mathbf{L}$ & $\Delta m=1.13 \mathbf{L}$ \\
\hline $\begin{array}{l}\text { Document } \\
\text { camera }\end{array}$ & & $\Delta m=0.46 \mathbf{M S}$ & $\Delta m=0.71 \mathbf{M L}$ & $\Delta m=0.96 \mathbf{L}$ \\
\hline Whiteboard & & & $\Delta m=0.25 \mathbf{M S}$ & $\Delta m=0.50 \mathrm{ML}$ \\
\hline $\begin{array}{l}\text { penTPC with } \\
\text { PowerPoint }\end{array}$ & & & & $\Delta m=0.26 \mathbf{M S}$ \\
\hline Key & $\begin{array}{c}\Delta m \leq 0.25 \\
\text { S Small effect }\end{array}$ & $\begin{array}{c}0.25 \leq \Delta m<0.50 \\
\text { MS medium-small }\end{array}$ & $\begin{array}{c}0.50 \leq \Delta m<0.75 \\
\text { ML medium-large }\end{array}$ & $\begin{array}{l}\Delta m \geq 0.75 \\
\text { L Large }\end{array}$ \\
\hline
\end{tabular}




\section{Analysis of student comments and relationship to ratings}

As discussed in the Study approach section, student comment responses associated with each mode rating were analysed to identify key categories/themes and these are shown in a quantitative summary in Table 7 . There were varying levels of response in the comment sections for each mode, and while most respondents mentioned only one issue, some responses covered more than one issue (with totals shown as response categories in Table 7). An initial categorisation of comments as to whether they were negative, positive, conditional (depends) or indeterminate (n/a) showed an ordering of modes broadly matching the preceding ratings order. While in the following discussion some emphasis is given to the more frequently and explicitly occurring comments, attention is also given to individual comments that appear to capture "something important in relation to overall research question” regardless of frequency (Vaismoradi, Turunen, \& Bondas, 2013, p. 403). The absence of explicit mention of a particular theme within a mode may also carry significance, with motivation for comments perhaps arising from comparative expectations of a mode rather than absolute judgements. Thus, the comments are used primarily to seek an understanding of the potential reasons influencing student effectiveness ratings, and as indicators of how modes might be improved, rather than as having direct quantitative significance for mode comparisons.

\section{Table 7}

Respondent comments by mode and category

(Note: Some respondent comments covered more than one category, and are included in both. Percentages of responses are calculated in terms of counts of respondents, so total percentages can add to $>100 \%$.)

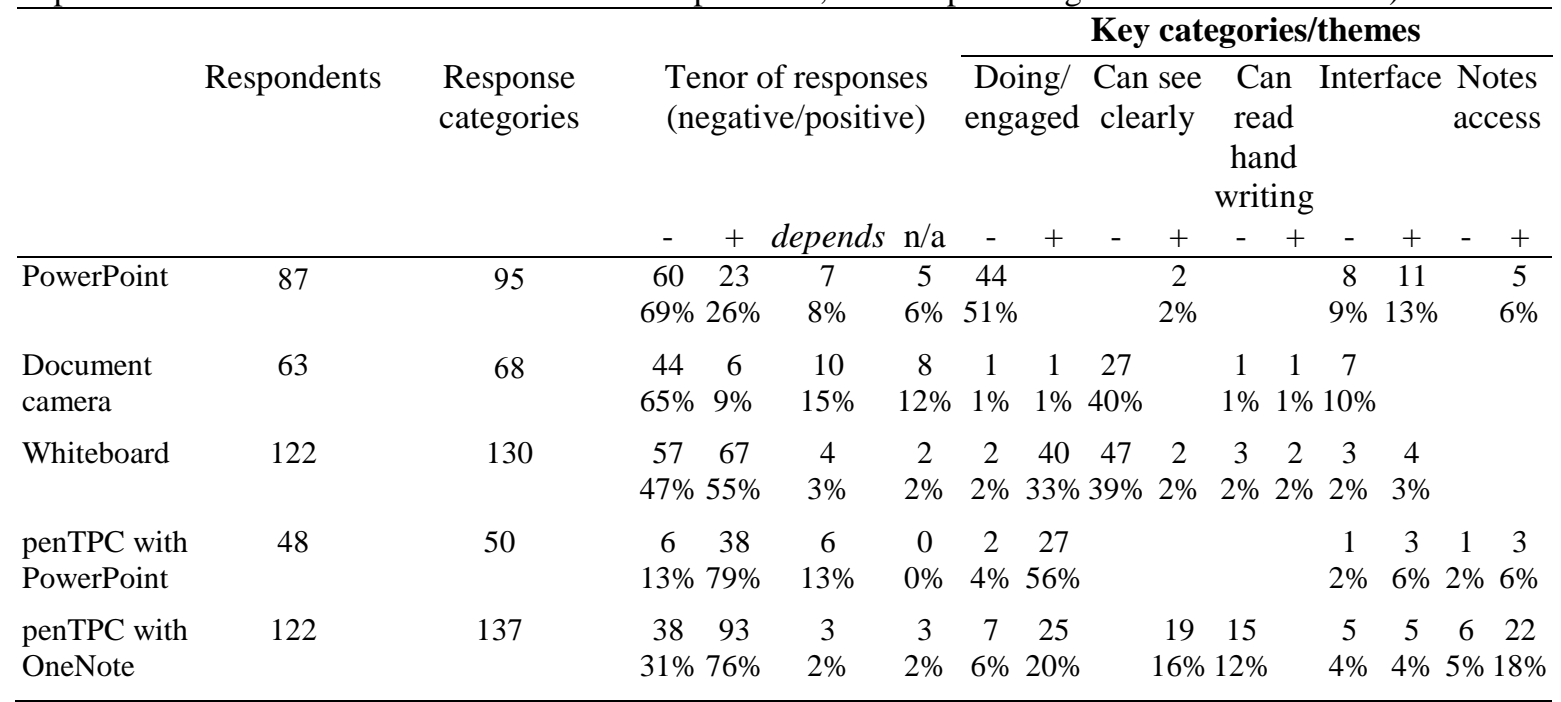

\section{PowerPoint}

Students in all sessions consistently rated the use of basic PowerPoint with prepared slides as the least effective mode. There were 95 classified comments from 87 respondents. The majority of the responses (60 from $69 \%$ of respondents) were essentially negative, with 44 comments (51\% of respondents) concerning lack of interactivity and engagement (and absence of annotation compared to the penTPC with PowerPoint mode), identified in Table 7 as a common theme of doing/engage:

Lack of engagement; not interactive enough and too easy to stop paying attention; do more example calculations regarding topic on slide; calculations [needed to] get info across; useful if you miss a lecture but boring in class; flicking through powerpoints rapidly is pointless; reading and not going through (material) is what we can do at home; too much info on the screen while the lecturer is talking; sometimes too much detail; lecture slides are rushed; sometimes lack the necessary details; unless used in conjunction with other method, it is useless. 
These comments echo the widespread criticism of PowerPoint expressed in a range of other studies across a range of disciplines (Berk, 2011; Craig \& Amernic, 2006; Levasseur \& Kanan Sawyer, 2006; Mann \& Robinson, 2009; Savoy, Proctor, \& Salvendy, 2009). The students in the study make it clear that basic PowerPoint does not meet their need to observe the lecturer dynamically demonstrate the reasoning processes underlying mathematical problem solving (Maclaren, 2014). The importance of seeing mathematics being done is also indicated by comments (5 or 6\%) that were supportive of the mode, but not for MI subjects:

Good for (some subjects) but not for maths; good for [non-mathematical] subject

There were 23 comments (26\% of respondents) identifying positive factors, mostly related to the structure and form of the presented material (interface $-13 \%$ of respondents), and as a source of notes (notes access - 6\% of respondents):

Clear and structural; everything is there and clearly shown; well prepared; the advantage of this is that the information is laid out nicely; good for showing notes that lecturer can talk about; everything is there and clearly shown.

However, a number commented negatively on the slide format, suggesting a single slide often carried too much detail to be copied and absorbed in the time it was visible. There were also conflicting comments, that slides "sometimes have too little detail", which might be reconciled by consideration of the subject material and the pace of presentation. If the lecturer is modelling expert thinking and developing complex procedural techniques, then full detail of the steps involved, presented at a slow pace, is essential. If factual information is presented at high density and rapidity (for example, flicking through slides containing large amounts of text), the student will have little time to absorb details. However, providing too little detail, and reducing textual information to bullet points, can remove essential context (Tufte, 2003). Finally, as one student states, reading information is something they can do outside class, and there are arguably better formats than standard PowerPoint slides for providing that information and, as revealed here, better modes for in-class presentation.

\section{Document camera}

Although the document camera is a standard and recommended feature in many universities for larger lecture rooms (AETM, 2015, p. 59), it is not generally available in smaller classrooms in the study institution. In larger rooms with minimal or no whiteboard capability, the document camera may be the only available presentation technology that supports handwriting. However, students judged the document camera to be the least effective of the handwritten modes and only slightly more effective than basic PowerPoint. Unlike other handwritten modes, there was little comment on the positive influence of mode on pace and engagement. Negative comments (44 from 65\% of respondents) dominated, with most of those ( 27 or $40 \%$ ) concerning the ability to see the material clearly (particularly focus):

Out of focus; blurry; not very clear; In most cases visibility issue; Unclear, hard to read

Although focus issues may be particular to the models of document camera installed in the study institution, there are factors of the interface inherent in the technology that are generic to all such devices: when in use the hand will be visible and at times may obscure, and distract from, the written material; the visible writing area, or field of view, is generally limited and requires frequent physical rearrangement of the writing surface (usually paper), with the loss to view of previously written material. Seven (10\%) respondents identified interface issues, such as:

Hand is always in the way ...; gets confusing switching between bits of paper and use of figures is difficult; viewing area too small, lose track, can’t follow; hand can get in the way and limited visibility time; hard to read handwriting sometimes. 
As with all handwritten approaches, there can be considerable variation between lecturer in their technique and handwriting capability, with individual comments both praising and lamenting handwriting techniques. Although there may be situations where the document camera has particular uses, such as in projecting views of physical artefacts, in this study environment at least, its inability to deliver material that could be clearly read overrode any potential benefits.

\section{Whiteboard}

The whiteboard is a traditional technology familiar to both students and staff for which usage approaches have been refined over time, and which has become a standard technology for the classroom teaching of mathematical disciplines (Fox \& Artemeva, 2011). There were 130 comments from 122 students. Just over half of the respondents (67 or 55\%) offered a positive comment, with most of those concerning pace of delivery and full exposition of problem-solving steps, as inherent in a handwritten approach:

Good if its done step by step and not too fast; includes important steps; it keeps the pace of the lecture reasonable and not too fast; like full working, don't like bullet points; effective as student has time to think during process; good as it (is) slower and we can take notes at the same pace as lecturer; engages the student very well

Although there were some comments, both positive and negative, about the quality of lecturer handwriting, it was (as with the document camera) not being able to see the content clearly (47 or 39\%) that was a critical negative issue, even for those who otherwise liked the mode:

Difficult to see; Often hard to see; cannot see whiteboard; Very hard to read; writing is often too small; difficult to see from the back; cannot see well if you sit at the back; sometimes its hard to read and not all the whiteboard markers work properly; Red pens are hard to read!!!!!; Ink too light/bright and can't see from far; good but sometimes hard to read; Great as long as the room is small enough to see the whiteboard; Very good to see working done but cannot be seen by all over class; I like it however the pens are often light or thin.

Visibility issues are a particular concern in larger rooms, from the back or from a side. Detailed recommendations concerning the visibility of material from a distance have been produced in relation to signage and projection of visual displays (AETM, 2015; Cai \& Green, 2009; van der Zanden, 2014). Factors addressed include the dimensions of the displayed elements (particularly element height and the width of the strokes forming the elements) in relation to distance from the material, viewing angles, illuminance, contrast between text elements and background, and the use of a positive contrast (dark text on light background) or negative (light text on dark background). It appears likely that these are issues that also need to be considered in presenting material on a whiteboard.

Within the study university, the lack of substantive whiteboard space in many rooms has been commented on by staff, and might be argued to have led to a sub-optimal experience of whiteboard mode for both lecturer and student. Some universities have boards that are able be raised after having been written on, but they are not available in the study university. Although vertically moveable boards allow a larger amount of material to become or remain visible after writing and before erasure, they do not address the issue of material being obscured while it is being written, and the fundamental issue of visibility from a distance remains. In some newer lecture theatres in the study university there are in fact no permanent whiteboards, and this has become a factor pushing lecturers toward the use of digital modes.

\section{PenTPC with PowerPoint and handwritten annotations}

The penTPC, used in conjunction with a data projector and associated screen, has been identified as a potential digital alternative to the traditional whiteboard (Maclaren, 2014). This survey intended to distinguish two software alternatives for use with a penTPC: one utilising pen annotations within PowerPoint (with PowerPoint slides forming the writing board) and the other using the pen within OneNote (with OneNote pages forming the 
writing board). However different developments in lecturer use of the penTPC have resulted in a range of variations in usage; in some instances, lecturers have made use of two data projectors (available in a few rooms), using one projector for PowerPoint (driven from a standard desktop PC) and the other projector for live developments with OneNote; in other instances, lecturers have used a whiteboard in conjunction with projecting standard PowerPoint. It is apparent that students may have had a range of variations in mind when rating the effectiveness of PowerPoint with handwritten annotations, and this needs to be kept in mind when examining student comments.

Students rated the use of the penTPC with live annotation of PowerPoint slides as the second most effective mode, being more effective than whiteboard mode and less effective than the use of the penTPC with OneNote. There were 50 comments from 48 students on the use of annotation with PowerPoint, with the majority (38 or 79\%) being positive. Many comments were related to the additional functionality (over standard PowerPoint), with annotation allowing dynamic development of material and calculations providing for better engagement (doing/engaged - 27 or 56\% of respondents). Typical comments were:

Better than std ppt and feels more interactive; Annotations are important; we need in class annotation to help understand the concepts; Annotations from class make things easier to understand; Without annotation some slides are hard to understand the second time; very useful to follow working through; I find annotation very important, when a lecturer can write examples, and explain problems; Helpful as they explain as you go; allows me to see step by step solutions which help with understanding; This is the most engaging and easiest to see.

Student comments indicate that the higher rating given for this mode over standard PowerPoint may be attributed to the reintroduction of a live handwritten mode. Rating this mode as more effective than whiteboard mode may be attributed to enhancements in visibility. Unsurprisingly, students wanted class sessions to include live development of mathematical processes but in a format that was clearly visible. Negative comments were related to not always having post-class access to material that included the annotations, and the format (of discrete slides) restricting viewing of earlier material:

Depends on subject as long as the updated slides are available for download; Adds detail to slides but can't see the previous notes

\section{PenTPC with OneNote}

The last mode considered involves the use of Microsoft OneNote in conjunction with a Tablet PCs and a data projector, and was the highest rating mode. This mode is of particular interest as it is becoming a common approach, acting as a digital whiteboard replacement (Maclaren, 2014) in many classes. It can provide essential affordances for handwritten input, as well as a suitable organisational structure that can be tailored to suit provision of class notes. The software can provide an effectively unlimited writing space on each page, ready navigation between and within pages (including zooming in and out of details) and customisable pens that allow different stroke widths and colours. It allows a combination of live handwritten material, prepared graphics and text and images to be delivered in conjunction with other software and video.

There were 137 categorised responses from 122 respondents on this mode, with 93 positive comments (76\% of respondents). Key references were to dynamic engagement (doing/engaged - 25 comments from 20\% of respondents), visibility (19 from 16\%) and note provision (22 from 18\%). Sample comments from each group are:

OneNote way best, as I could understand steps and method; very useful to follow working through; I like it because it gives a clear understanding of the material; easily accessible notes online and step by step process helps with learning

Can see the board wherever you sit; easy to read and always high contrast (pen can't run out of ink); Same as the board but more clear and bigger to see. 
Good because notes can be uploaded; Great if uploaded to AUTonline; Lecturer can post it up later; I like this best because it allows the lecturer to record the lessons with ease;

Some negative comments reflected capabilities that were not being utilised by some lecturers:

would be better if the lecturer's notes were uploaded for students access online

These comments again illustrate that students want steps involved in mathematical procedural thinking to be developed live, and (obviously) need that material to be clearly visible from anywhere in the room, and are concerned to have access to notes outside the class.

There are a number of issues related to notetaking by students and note provision by lecturers, and changing expectations of and from students and lecturers of the types of activities to be conducted both inside and outside the classroom. The penTPC with OneNote mode provides ready access to a range of options for recording, and although at this time there is no consistent approach by lecturers, student comments make it clear that they consider access to a record of the lecturer notes as a valuable feature where it has been made available. As with all handwritten modes, there remain issues related to the legibility of the lecturer's handwriting and expertise in using the technology, and these accounted for the majority of the negative comments (15 from $12 \%$, of respondents):

Only good if the lecturer is able to use their tablet, has good handwriting. Handwriting need to be better; As long as legible. Handwriting a factor

Student comments also recorded the fact that the mode is not limited to presenting handwritten material:

Can bring in figures and tables into notes.

Singer and Smith (2013, p. 470) reported on the importance of using multiple forms of representations in instruction, including "realistic (picture or text), diagrammatic (free body diagram) and symbolic (mathematical)“ representations. Oviatt (2013, p. 61) stressed the importance of using interfaces that support “expression of non-linguistic representations, including diagrams, symbols, numbers, and informal marking”. The Tablet PC environment provides for these combinations of digital representations that are difficult to support in keyboard-based digital interfaces in conjunction with traditional handwritten board technologies. Although many smaller classrooms are equipped with both data projection screens and whiteboard in some form, there are often conflicting requirements in both placement and lighting that can make use of the two modes together less satisfactory.

Within the classroom (and outside), access is no longer limited to what has not already been erased. Although not continuously in the field of view, previously written notes (even from earlier sessions) can be scrolled back into visibility by the lecturer at any time, and parts of interest can be zoomed in on to allow inspection of detail. As the following comment shows, in one class (at least) a lecturer has been making use of the capability to share OneNote notebooks live, providing students with access to the notes as they are being developed, and providing potential capability for students to use their own devices to independently scroll through material:

OneNote is a great tool and viewing it live allows me to jump back in time to notes he's moved on from; One thing I like is how it updates in real time to my laptop, so if he speeds ahead I can go back;

In making their judgement on this mode, students will have encountered lecturers with a range of experience in using the penTPC mode, including a number in their first semester of use. Despite being at an early stage of development, the study has shown the penTPC OneNote mode to have the highest student rating, being judged significantly better than all other modes. Although some common practices are beginning to be observed, the development of guidelines for good practice may further enhance the effectiveness of use of this mode. 


\section{Conclusions}

Students surveyed in this study, who were being taught MI engineering subjects in a classroom environment, rated the effectiveness of different delivery modes as ordered below (worst to best):

PowerPoint $\rightarrow$ Document camera $\rightarrow$ whiteboard $\rightarrow$ penTPC with PowerPoint $\rightarrow$ penTPC with OneNote

These differences between student ratings of modes were statistically significant, and effect sizes were meaningfully large.

Student comments on likes/dislikes suggest that ratings of effectiveness are influenced by placing higher value on teaching technology modes that support the key categories/themes as identified in Table 7:

- $\quad$ enable the display of live, step-by-step development of theory and problem solution (doing/engaged)

- display material in a format that is clearly visible, with legible writing, throughout the class environment (can see clearly), (can read handwriting)

- enable inclusion of other material, such as figures and tables (interface)

- can provide a record of notes that can be made available online (notes access).

The strong student preference for the use of penTPCs as a classroom delivery mode revealed in this study can be explained by the strong support that this mode affords all of these factors. The results suggest that students share the values identified by lecturers of the importance of the explicit modelling of expert thinking as a key component of the teaching sessions. The specific issues of student notetaking in class and lecturer provision of notes (both prior and post a session) in the context of developments in software and pedagogical approaches are also issues identified for further examination as part of the larger design research project to which this survey contributes.

This research has implications across a range of institutional roles and functions. Although student preferences have been clearly established, there are other considerations, including financial issues that need to be considered. If use of penTPC technology is to become a teaching standard, managers will need to ensure that institutional policies and procedures enable all teaching staff engaged in these areas to have access to such a device, particularly given pressure from students for its adoption. Information and computing technology (ICT) support services need to be skilled in supporting this mobile technology, which may have different requirements from desktop PCs. Planned, structured institutional support is essential for successful introduction of new educational technologies (Elzarka, 2012; Schoepp, 2005).

For those in charge of space management and development (estates management), the requirements for the generic classroom may need to change if the Tablet PC is to becomes a standard for classroom delivery. The physical layout and height of lecterns and positioning of cables may benefit from redesign to better support Tablet writing, and provision of suitable (high definition) data projectors and screens in all rooms becomes essential. The document camera might be determined to be unnecessary as a standard item; even where there is the need to project views of physical artefacts, a stand to support a Tablet equipped with a suitable web camera might be sufficient.

This study looked at delivery modes for MI subjects in a traditional classroom environment. The importance placed on demonstration of procedural development using handwritten approaches has been a factor that has supported the ongoing use of the traditional lecture style format in the mathematics classroom. It is apparent from this study that the students regard the penTPC as providing an effective and preferred technology for maintenance of this approach, especially within larger classrooms. It is also apparent that there is scope for refinement in the techniques for use of the technology that may be aided by the development of guidelines for its effective use. 
Puentedura (2010) described technology as having the potential to be used in a progression, at a level of substitution, augmentation, modification or redefinition (abbreviated as SAMR). Models such as TPACK (Harris et al., 2009) investigate more complex interactions between pedagogy, content knowledge and technology, often involving the use of technology by students, rather than just by lecturers. However, in this study the penTPC was used by lecturers as a substitute for, or a functional improvement over, the whiteboard, without substantive changes in pedagogy. To recast the earlier quote from Annan (2008, p. 16), it appears from this study that the introduction of the technology may be facilitated because faculty and students are "convinced of the relevance of the technology to what they [currently] do" and because there is no immediate need "to change their current practices”.

However, enabling faculty to become fluent in the use of a technology for familiar academic tasks and even personal uses, as advocated by Elzarka (2012), may make it easier to subsequently introduce pedagogical changes that take fuller advantage of the affordances of the technology. By providing support for delivering and recording handwriting in all forms of a digital environment, the penTPC has the potential to enable substantive modification and redefinition of learning and teaching approaches, with reconsideration of what is best done in class and what is best done outside of class. When students, and not just the lecturers, have guaranteed access to these devices the scope for change is further enhanced.

Thus, it is the capabilities of the technology to redefine how MI classes are taught in the modern university, by enabling interactions that have previously been possible only within the classroom to be conducted within online environments, that may provide the most compelling arguments for its adoption.

\section{References}

Abrahams, D. A. (2010). Technology adoption in higher education: a framework for identifying and prioritising issues and barriers to adoption of instructional technology. Journal of Applied Research in Higher Education, 2(2), 34-49. doi:10.1108/17581184201000012

AETM. (2015). Audio visual design guidelines: Tertiary teaching spaces (2nd ed.). Retrieved from https://www.aetm.org/wpcontent/uploads/2014/10/AETM_Audio_Visual_Design_Guidelines_2nd_Edtion_2015_protected.pdf

Anderson, T., \& Shattuck, J. (2012). Design-based research: A decade of progress in education research? Educational Researcher, 41(1), 16-25. doi:10.3102/0013189X11428813

Annan, D. L. (2008). Facilitating adoption of technology in higher education. Distance Learning, 5(1), 13-17. Retrieved from https://content.usdla.org/wp-content/uploads/2015/09/Vol.-5-No.-1-2008.pdf

Baguley, T. (2009). Standardized or simple effect size: What should be reported? British Journal of Psychology, 100(3), 603-617. doi:10.1348/000712608X377117

Bates, T. (2014). Methods of teaching. In Teaching in a digital age. Retrieved from http://opentextbc.ca/teachinginadigitalage/chapter/chapter-4-methods-of-teaching/

Bedford, C. (2013, January 31). R code for executing the Marascuilo procedure on all pairwise combinations of proportion differences from a contingency table [Blog post]. Build Lackey Blog. Retrieved from http://buildlackey.com/r-code-for-executing-the-marascuilo-procedure-on-all-pairwise-combinations-ofproportion-differences-from-a-contingency-table/

Bergsten, C. (2007). Investigating quality of undergraduate mathematics lectures. Mathematics Education Research Journal, 19(3), 48-72. doi:10.1007/BF03217462

Berk, R. A. (2011). Research on PowerPoint ${ }^{\circledR}$ : From basic features to multimedia. International Journal of Technology in Teaching and Learning, 7(1), 24-35. Retrieved from http://www.ronberk.com/articles/2011_research.pdf

Braun, V., \& Clarke, V. (2006). Using thematic analysis in psychology. Qualitative Research in Psychology, 3(2), 77-101. doi:10.1191/1478088706qp063oa

Brooks, M. E., Dalal, D. K., \& Nolan, K. P. (2014). Are common language effect sizes easier to understand than traditional effect sizes? Journal of Applied Psychology, 99(2), 332-340. doi:10.1037/a0034745

Cai, H., \& Green, P. A. (2009). Legibility index for examining common viewing situations: A new definition using solid angle. Leukos, 5(4), 279-295. doi:10.1582/LEUKOS.2008.05.04.002 
Cliff, N. (1993). Dominance statistics: Ordinal analyses to answer ordinal questions. Psychological Bulletin, 114(3), 494-509. doi:10.1037/0033-2909.114.3.494

Coe, R. (2002, September). It's the effect size, stupid: What effect size is and why it is important. Paper presented at the Annual Conference of the British Educational Research Association, University of Exeter, England. Retrieved from http://www.leeds.ac.uk/educol/documents/00002182.htm

Craig, R. J., \& Amernic, J. H. (2006). PowerPoint presentation technology and the dynamics of teaching. Innovative Higher Education, 31(3), 147-160. doi:10.1007/s10755-006-9017-5

Elzarka, S. (2012). Technology use in higher education instruction (Doctoral Dissertation). Claremont Graduate University, Claremont, CA. Retrieved from http://scholarship.claremont.edu/cgu_etd/39/

Feng, D. (2007). Robustness and power of ordinal d for paired data. In S. Sawilowsky (Ed.), Real data analysis (pp. 163-183). Charlotte, NC: Information Age Publishing.

Feng, D., \& Cliff, N. (2004). Monte Carlo evaluation of ordinal d with improved confidence interval. Journal of Modern Applied Statistical Methods, 3(2), 322-332. Retrieved from http://digitalcommons.wayne.edu/jmasm/vol3/iss2/6/

Fox, J., \& Artemeva. (2011). The cinematic art of teaching university mathematics: Chalk talk as embodied practice. Multimodal Communication, 1(1), 83-103. doi:10.1515/mc-2012-0007

Greiffenhagen, C. (2008). Video analysis of mathematical practice? Different attempts to "open up" mathematics for sociological investigation. Forum Qualitative Sozialforschung/Forum: Qualitative Social Research, 9(3). Retrieved from http://www.qualitative-research.net/index.php/fqs/article/viewArticle/1172

Greiffenhagen, C. (2014). The materiality of mathematics: Presenting mathematics at the blackboard. The British Journal of Sociology, 65(3), 502-528. doi:10.1111/1468-4446.12037

Grissom, R. J., \& Kim, J. J. (2005). Effect sizes for research: A broad practical approach. Mahwah, NJ: Erlbaum.

Harris, J., Mishra, P., \& Koehler, M. (2009). Teachers' technological pedagogical content knowledge and learning activity types: Curriculum-based technology integration reframed. Journal of Research on Technology in Education, 41(4), 393-416. doi:10.1080/15391523.2009.10782536

Hess, M. R., \& Kromrey, J. D. (2004, April). Robust confidence intervals for effect sizes: A comparative study of Cohen's $d$ and Cliff's delta under non-normality and heterogeneous variances. Paper presented at the Annual meeting of the American Educational Research Association, San Diego, CA. Retrieved from http://www.coedu.usf.edu/main/departments/me/documents/cohen.pdf

Knapp, T. R. (2009). Percentages: The most useful statistics ever invented. Retrieved from http://www.statlit.org/pdf/2009Knapp-Percentages.pdf

Kraemer, H. C., \& Kupfer, D. J. (2006). Size of treatment effects and their importance to clinical research and practice. Biological Psychiatry, 59(11), 990-996. doi:10.1016/j.biopsych.2005.09.014

Levasseur, D. G., \& Kanan Sawyer, J. (2006). Pedagogy meets PowerPoint: A research review of the effects of computer-generated slides in the classroom. Review of Communication, 6(1-2), 101-123. doi:10.1080/15358590600763383

Maclaren, P. (2014). The new chalkboard: The role of digital pen technologies in tertiary mathematics teaching. Teaching Mathematics and Its Applications, 33(1), 16-26. doi:10.1093/teamat/hru001

Mann, S., \& Robinson, A. (2009). Boredom in the lecture theatre: An investigation into the contributors, moderators and outcomes of boredom amongst university students. British Educational Research Journal, 35(2), 243-258. doi:10.1080/01411920802042911

Marascuilo, L. A. (1966). Large-sample multiple comparisons. Psychological Bulletin, 65(5), 280. doi:10.1037/h0023189

McKeachie, W., \& Svinicki, M. (2013). McKeachie’s teaching tips. Belmont, CA: Cengage Learning, Wadsworth.

Miles, M. B., \& Huberman, A. M. (1994). Qualitative data analysis: An expanded sourcebook. Thousand Oaks, CA: Sage.

Oviatt, S. (2013). The design of future educational interfaces. New York, NY: Routledge.

Oviatt, S., Cohen, A., Miller, A., Hodge, K., \& Mann, A. (2012). The impact of interface affordances on human ideation, problem solving, and inferential reasoning. ACM Transactions on Computer-Human Interaction, 19(3), 1-30. doi:10.1145/2362364.2362370

Peng, C.-Y. J., \& Chen, L.-T. (2014). Beyond Cohen’s d: Alternative effect size measures for between-subject designs. The Journal of Experimental Education, 82(1), 22-50. doi:10.1080/00220973.2012.745471 
Prins, J. (Ed.). (2013). Product and process comparison. In NIST/SEMATECH e-Handbook of statistical methods. Retrieved from http://www.itl.nist.gov/div898/handbook/prc/section4/prc474.htm

Puentedura, R. (2010). SAMR and TPCK: Intro to advanced practice. Retrieved from http://hippasus.com/resources/sweden2010/SAMR_TPCK_IntroToAdvancedPractice.pdf

R Project. (2015). R: The R Project for Statistical Computing. Retrieved from https://www.r-project.org/

Rogers, E. M. (1983). Diffusion of innovations. New York, NY: Free Press.

Rogmann, J. J. (2013). Ordinal Dominance Statistics (orddom): An R Project for Statistical Computing package to compute ordinal, nonparametric alternatives to mean comparison (Version 3.1). Retrieved from ftp://videolan.cs.pu.edu.tw/network/CRAN/web/packages/orddom/orddom.pdf

Romano, J., Kromrey, J. D., Coraggio, J., Skowronek, J., \& Devine, L. (2006, October). Exploring methods for evaluating group differences on the NSSE and other surveys: Are the t-test and Cohen's $d$ indices the most appropriate choices? Paper presented at the Annual meeting of the Southern Association for Institutional Research, Arlington, VA. Retrieved from http://www.coedu.usf.edu/main/departments/me/documents/MethodsforEvaluatingGroup.pdf

Sandoval, W. (2014). Conjecture mapping: An approach to systematic educational design research. Journal of the Learning Sciences, 23(1), 18-36. doi:10.1080/10508406.2013.778204

Savoy, A., Proctor, R. W., \& Salvendy, G. (2009). Information retention from PowerPoint and traditional lectures. Computers \& Education, 52(4), 858-867. doi:10.1016/j.compedu.2008.12.005

Schoepp, K. (2005). Barriers to technology integration in a technology-rich environment. Learning and Teaching in Higher Education: Gulf Perspectives, 2(1), 1-24. Retrieved from http://www.zu.ac.ae/lthe/vol2no1/lthe02_05.pdf

Selwyn, N. (2010). Looking beyond learning: Notes towards the critical study of educational technology: Looking beyond learning. Journal of Computer Assisted Learning, 26(1), 65-73. doi:10.1111/j.13652729.2009.00338.x

Singer, S., \& Smith, K. A. (2013). Discipline-based education research: Understanding and improving learning in undergraduate science and engineering. Journal of Engineering Education, 102(4), 468-471. doi:10.1002/jee.20030

Tufte, E. R. (2003). The cognitive style of PowerPoint. (Vol. 2006). Cheshire, CT: Graphics Press.

Vaismoradi, M., Turunen, H., \& Bondas, T. (2013). Content analysis and thematic analysis: Implications for conducting a qualitative descriptive study. Nursing \& Health Sciences, 15(3), 398-405. doi:10.1111/nhs. 12048

van der Zanden, A. P. (2014). Readability in classrooms. Retrieved from http://www.adaptivespaces.co.uk/index_htm_files/Readability_in_Classrooms.pdf

Velleman, P. F., \& Wilkinson, L. (1993). Nominal, ordinal, interval, and ratio typologies are misleading. The American Statistician, 47(1), 65-72. doi:10.1080/00031305.1993.10475938

Corresponding author: Peter Maclaren, peter.maclaren@aut.ac.nz

Australasian Journal of Educational Technology (C) 2017.

Please cite as: Maclaren, P., Wilson, D., \& Klymchuk, S. (2017). I see what you are doing: Student views on lecturer use of Tablet PCs in the engineering mathematics classroom. Australasian Journal of Educational Technology, 33(2), 173-188. https://doi.org/10.14742/ajet.3257 